\title{
On the Temperature Dependence of Complex Formation between Chitosan and Proteins
}

\author{
Marina R. Kasimova, ${ }^{*,+}$ Adrián Velázquez-Campoy, ${ }^{\dagger}$ and Hanne M. Nielsen ${ }^{*,+}$ \\ ${ }^{\dagger}$ Department of Pharmaceutics and Analytical Chemistry, Pharmaceutical Sciences, University of Copenhagen, \\ Universitetsparken 2, 2100 Copenhagen, Denmark \\ ${ }^{\ddagger}$ Institute of Biocomputation and Physics of Complex Systems, Universidad de Zaragoza, 50018 Zaragoza, Spain, \\ Unidad Asociada BIFI-IQFR, CSIC, Spain, and Fundacion ARAID, Diputacion General de Aragon, Spain
}

Supporting Information

ABSTRACT: Chitosan is a biocompatible easily degradable polysaccharide, which, because of its positive charge, is able to interact favorably with deprotonated carboxyl groups of proteins. The strength of these charge-charge interactions is generally low, resulting in poor colloidal stability of the complexes. To investigate if other noncovalent forces contribute to stabilizing such systems, we have selected $\alpha$-lactalbumin, $\beta$ lactoglobulin, $\beta$-casein, and human growth hormone, characterized by a common acidic pI value $(\sim 5)$ that ensures their overall negative charge at physiological $\mathrm{pH}$. Binding energetics between chitosan and proteins was studied by isothermal titration calorimetry, whereas the thermal stability was assessed by
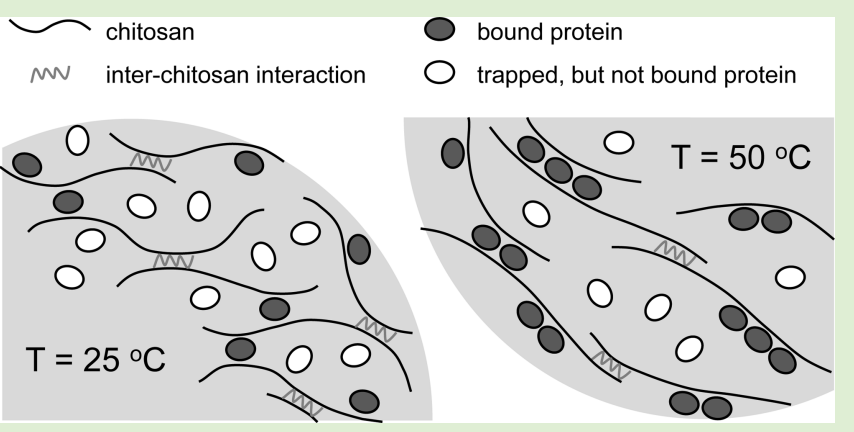
differential scanning calorimetry. Our data show that colloidal stability of the particles depends on protein identity as well as temperature, indicating the involvement of nonelectrostatic interactions (e.g., hydrophobic effect) as driving forces for the complex formation. This suggests that chitosan-protein drug delivery systems can be improved through preparation process optimization with regard to temperature.

\section{INTRODUCTION}

Chitosan (CS) is a linear polysaccharide that because of its accessibility and biocompatibility has numerous applications in agriculture, food industry, cosmetics, and increasingly so in pharmaceutical sciences. CS is produced by deacetylation of chitin, a polymer closely related to cellulose. The unmodified chitin is insoluble in water, whereas the CS is much more soluble in aqueous media because of the presence of a high number of amine groups. The CS molecule is positively charged below physiological $\mathrm{pH}\left(\mathrm{p} K_{\mathrm{a}}(\mathrm{CS}) \approx 6.5\right)$. $^{1}$ Biocompatibility of $\mathrm{CS}$, together with its suggested ability to open the tight junctions between epithelial cells ${ }^{2}$ and thus facilitate the delivery of pharmaceutical macromolecules across epithelium, ${ }^{3}$ spurred its use in biomedical applications in general (for review, see Berger et al. ${ }^{4}$ ) and in pharmaceutical formulations of proteins in particular. ${ }^{5}$ However, the major drawback of the CS-based particulate systems is their low colloidal stability in suspension because they undergo fusion, precipitation, and disintegration or dissolution upon storage and after administration. ${ }^{6-8}$

The problem is usually approached by the addition of crosslinking agents that stabilize individual particles and prevent the collapse of CS formulations. The ionic gelation method, a very popular approach, is based on the favorable electrostatic interaction between the positively charged CS molecules and the polymeric anions, such as tripolyphosphate (TPP), ${ }^{9}$ poly- $\gamma$-glutamic acid $(\gamma$-PGA $),{ }^{5}$ alginate,${ }^{10,11}$ or a combination of these. ${ }^{12}$ Because success of the ionic gelation method relies on the presence of opposite charges on the two interacting macromolecules, stability of the resulting particles can be improved by varying the $\mathrm{pH}^{9,13}$ and the ionic strength of the solution. ${ }^{14}$ The influence of these factors on particle formation has been investigated by several groups ${ }^{5,13,15}$ with the same overall conclusion that $\mathrm{pH}$ is a determining factor for the CS particle formation and colloidal stability. For example, it has been shown that insulincontaining particles having been cross-linked by $\gamma$-PGA ${ }^{5}$ become unstable and disintegrate at $\mathrm{pH} 1.2$ ( $\mathrm{pH}$ of the stomach) and the physiological $\mathrm{pH}$ of 7.4, that is, under the conditions where either CS or $\gamma$-PGA become less charged. Also, CS-caseinate particles that form successfully at $\mathrm{pH} 5.0$ to 6.0 aggregate with a consequent phase separation at $\mathrm{pH}$ values $<4$ or $>6.5$. $^{15}$ Another problem resulting from the limited stability of the CS-based formulations is their poorly controlled release profiles, characterized by a high burst release. ${ }^{13,16-18}$ This release profile indicates insufficiency of the electrostatic forces for stabilizing the poly ion complexes. Furthermore, the weakness of the charge-charge interactions in $\mathrm{CS}$-insulin and $\mathrm{CS}$-benzoic

\footnotetext{
Received: March 14, 2011

Revised: $\quad$ May 5, 2011

Published: May 19, 2011
} 
Table 1. Physico-Chemical Characteristics of the Model Proteins

\begin{tabular}{|c|c|c|c|c|}
\hline protein & $\begin{array}{l}\text { MW } \\
(\mathrm{kDa})\end{array}$ & $\mathrm{pI}$ & $\begin{array}{c}\mathrm{CMC} \\
(\mathrm{mg} / \mathrm{mL})^{a}\end{array}$ & $2^{\prime}$ structure \\
\hline$\alpha$-lactalbumin & 14.2 & $5.0^{b}$ & 0.3 & mostly $\alpha$-helix \\
\hline$\beta$-lactoglobulin & 18.4 & $4.5^{b}$ & 0.3 & mostly $\beta$-sheet \\
\hline$\beta$-casein & 24.0 & $5.5^{b}$ & 0.35 & naturally unstructured \\
\hline human growth hormone & 22.1 & $5.3^{c}$ & & $\alpha$-helix bundle \\
\hline
\end{tabular}

acid particles is experimentally confirmed in direct measurements of the binding strength by isothermal titration calorimetry (ITC) ${ }^{19}$ combined with ${ }^{1} \mathrm{H}$ NMR and FTIR. ${ }^{20}$

Despite the problems associated with the production and storage stability of the CS-based formulations as well as the limited stability at physiologically relevant $\mathrm{pH}$ values, $\mathrm{CS}$ remains an attractive excipient, and the search for more successful formulation strategies continues, with the majority of the work being concentrated on improving the ionic gelation technique.

In addition to its ionic nature, another major property of CS is its hydrophobicity, the extent of which can be controlled by chemical modifications ${ }^{21}$ or by varying degree of deacetylation (DD). In addition, increasing the solution concentration of CS induces intermolecular aggregation, accompanied by the formation of hydrophobic domains. ${ }^{22}$ The available data suggest that even in the absence of the electrostatic attraction, CS can interact with bovine serum albumin ${ }^{21}$ and insulin ${ }^{13}$ through hydrophobic interactions and $\mathrm{H}$-bonds, indicating that these forces can be successfully exploited for the stabilization of the CS formulations. The problem with this approach is that the increased hydrophobicity of CS reduces its solubility in aqueous medium as well as promotes aggregation of the CS-based particles. In this regard, it would be ideal to improve the hydrophobic part of the interaction while maintaining the electrostatic contribution optimal.

Here we aim to investigate whether the particle preparation can be optimized by performing the formulation procedure at different temperatures. In addition, we explore the possibility of achieving CS-based nanoparticles by using proteins only, thus avoiding any other unnecessary additives. Three model proteins, $\alpha$-lactalbumin ( $\alpha$-la), $\beta$-lactoglobulin $(\beta$-lg), and $\beta$-casein $(\beta$-ca), with different inherent fold (Table 1), were selected on the basis of their acidic isoelectric point ( $\mathrm{pI}$ ) values (Table 1), a property important for ensuring their overall negative charge at near-physiological $\mathrm{pH}$. All three proteins have surfactant activity, ${ }^{23}$ which would be another potential contributor to the stabilization of the particle-water interface. In addition, the same approach is applied to a pharmaceutically relevant protein, human growth hormone (hGH).

\section{MATERIALS AND METHODS}

Materials. Ultrapure chitosan glutamate (PROTASAN UP G213) was purchased from NovaMatrix (Drammen, Norway) with reported molecular weight of $213000 \mathrm{~g} / \mathrm{mol}$ and $83 \%$ deacetylation degree (DD) and used as supplied. hGH was kindly provided by Novo Nordisk A/S (Måløv, Denmark), $\alpha$-lactalbumin, $\beta$-lactoglobulin, $\beta$-casein, and other chemicals were purchased from Sigma-Aldrich and used as supplied. (Information on the purity of the proteins provided by the producer: $\alpha$-la, calcium depleted, purity $\geq 85 \%$, batch no. $106 \mathrm{H} 8295 ; \beta$ - $\lg -90 \%$ pure (PAGE), batch no. 097K7012; $\beta$-ca. - 90\% pure, batch nos. $087 \mathrm{~K} 7425$ and $105 \mathrm{~K} 7410$.)
Preparation of Chitosan-Protein Particles. CS was dissolved in Milli-Q water to the final concentration of $2 \mathrm{mg} / \mathrm{mL}$. The model proteins were dissolved in $10 \mathrm{mM}$ phosphate buffer of appropriate $\mathrm{pH}$ (5.5, 6.0, or 6.5), and the exact concentration of each protein was determined spectrophotometrically using the following extinction coefficients at $280 \mathrm{~nm}$ : $\alpha$-lactalbumin, $2.01(\mathrm{mg} / \mathrm{mL} \cdot \mathrm{cm})^{-1}($ Sigma-Aldrich, product information); $\beta$-lactoglobulin, $0.96(\mathrm{mg} / \mathrm{mL} \cdot \mathrm{cm})^{-1}$; $\beta$-casein, ${ }^{24} 0.46(\mathrm{mg} / \mathrm{mL} \cdot \mathrm{cm})^{-1}$. The protein stock concentration used for particle preparation was $2 \mathrm{mg} / \mathrm{mL}$.

The formation of the nanoparticles was initiated by mixing equal parts (usually $1 \mathrm{~mL}$ each) of CS and protein stock solutions, resulting in the final concentrations of $1 \mathrm{mg} / \mathrm{mL}$ for both components and buffer strength of $5 \mathrm{mM}$. The stirring rate was typically $\sim 300 \mathrm{rpm}$. After the mixing, $\mathrm{pH}$ was checked and adjusted with the minimal amount (typically $<20 \mu \mathrm{L}$ ) of $\mathrm{HCl}$ or $\mathrm{NaOH}$ to one of the three experimental $\mathrm{pH}$ values: $5.5,6.0,6.5$. These were selected to fall within the limits defined by the $\mathrm{p} K_{\mathrm{a}}$ of CS, 6.5, and the $\mathrm{pI}$ values of the proteins, $\sim 5$. The mixture was maintained at the preparation temperature, chosen within the range of $25-80^{\circ} \mathrm{C}$, for 15 min under continuous stirring with a magnetic stirrer. After determination of the particle size and $\zeta$-potential, the formulations were kept at $4{ }^{\circ} \mathrm{C}$ for evaluation of the colloidal stability.

Particle Characterization. The mean particle size was measured by dynamic light scattering (DLS) using the Zetasizer Nano ZS (Malvern Instruments, Grovewood, U.K.) equipped with $633 \mathrm{~nm}$ laser and $173^{\circ}$ detection optics. A nanosphere size standard $(60 \pm 2.7 \mathrm{~nm})$ was used to verify the performance of the instrument. All samples were measured in triplicates. The $\zeta$-potential of the particles was measured by the laser Doppler electrophoresis technique using the Malvern NanoZS. A $\zeta$ potential transfer standard $(-68 \pm 6.8 \mathrm{mV})$ from Malvern was used to verify the performance of the instrument. Malvern DTS v.5.10 software (Malvern Instruments, Worcestershire, United Kingdom) was used for data acquisition and analysis. For viscosity and refractive index, the values of pure water were used. Measurements of mean particle size and $\zeta$-potential were performed at $25^{\circ} \mathrm{C}$ on the solutions with 20 times dilution of the original sample in $5 \mathrm{mM}$ phosphate buffer. All samples were measured in triplicate.

For imaging of the particles, cryo-transmission electron microscopy (Cryo-TEM) was applied. CS-protein sample $(5 \mu \mathrm{L}, \beta$-lactoglobulin) in buffer was added to negatively charged coated lacey carbon film copper grids, excess liquid was removed by careful blotting with absorbent filter paper leaving a thin $(<300 \mathrm{~nm})$ biconcave liquid film spanning the holes of the carbon grid. The sample was rapidly plunged into liquid ethane $\left(-180^{\circ} \mathrm{C}\right)$ and cooled by liquid nitrogen to obtain a vitrified film. This was stored under liquid nitrogen and transferred in a cryoholder (Oxford CT3500), and its workstation was used to transfer the specimen into the electron microscope (Philips CM120 BioTWIN Cryo) equipped with a postcolumn energy filter (Gatan GIF100). The acceleration voltage was $120 \mathrm{kV}$. The images were recorded digitally with a CCD camera under low electron dose conditions.

Colloidal Stability of the Chitosan-Protein Particles. Stability of the CS-protein particles in suspension was assessed by their resistance to precipitation during storage at $4{ }^{\circ} \mathrm{C}$. The samples were checked daily for visual signs of precipitation, and their diameter together with $\zeta$-potential were measured daily during the first week after preparation. Prior to each measurement, the samples were agitated and diluted as described above. Subsequently, the particles were evaluated weekly. Aggregation of the samples could sometimes be detected by eye, as a layer of precipitate accumulated on the bottom of the test vials. The precipitate had a white snow-like appearance, and it could not be resuspended by shaking. Formation of aggregates was, however, also apparent during the size determination: the quality of the measured mean diameter values became unstable, the size increased in value, or both.

Isothermal Titration Calorimetry. Investigation of the binding of CS to the model proteins was done either on Nano ITC (TA Instruments, New Castle, DE) or on MicroCal VP-ITC (Piscataway, 
Table 2. DLS Results on the Size of CS-Protein Particles Immediately after Preparation under Different Conditions

\begin{tabular}{|c|c|c|c|c|c|c|c|c|c|}
\hline \multirow{3}{*}{$T_{\text {prep }}\left({ }^{\circ} \mathrm{C}\right)$} & \multicolumn{9}{|c|}{ diameter of the particles $(\mathrm{nm})^{a}$} \\
\hline & \multicolumn{3}{|c|}{$\beta$-lactoglobuling $/ \mathrm{pH}$} & \multicolumn{3}{|c|}{$\alpha$-lactalbumin $/ \mathrm{pH}$} & \multicolumn{3}{|c|}{$\beta$-casein $/ \mathrm{pH}$} \\
\hline & 5.5 & 6.0 & 6.5 & 5.5 & 6.0 & 6.5 & 5.5 & 6.0 & 6.5 \\
\hline 25 & $370 \pm 30$ & $240 \pm 40$ & 327 & $360 \pm 20$ & $400 \pm 100$ & 340 & $330 \pm 20$ & $490 \pm 60$ & $440 \pm 90$ \\
\hline 50 & $350 \pm 50$ & $220 \pm 10$ & 203 & $270 \pm 20$ & $290 \pm 40$ & 380 & $350 \pm 20$ & $440 \pm 40$ & $500 \pm 50$ \\
\hline 60 & $370 \pm 50$ & $240 \pm 20$ & 348 & $260 \pm 40$ & $360 \pm 90$ & 460 & $320 \pm 20$ & $370 \pm 40$ & $500 \pm 20$ \\
\hline 70 & $330 \pm 70$ & $200 \pm 20$ & $* b$ & $250 \pm 20$ & $330 \pm 80$ & 340 & $300 \pm 20$ & $360 \pm 30$ & * \\
\hline 80 & $410 \pm 20$ & $270 \pm 20$ & * & $250 \pm 20$ & $370 \pm 110$ & 310 & $310 \pm 20$ & $350 \pm 30$ & * \\
\hline
\end{tabular}

${ }^{a}$ Mean and standard deviation values were calculated using the data from two different batches. ${ }^{b}$ Preparations marked with asterisk $\left({ }^{*}\right)$ precipitated immediately upon mixing.

Table 3. Charge of CS-Protein Particles at Different Preparation Conditions and the Protein Molecular Charge

\begin{tabular}{|c|c|c|c|c|c|c|c|c|c|}
\hline \multirow{3}{*}{$T_{\text {prep }}\left({ }^{\circ} \mathrm{C}\right)$} & \multicolumn{9}{|c|}{$\zeta$-potential $(\mathrm{mV})^{a}$} \\
\hline & \multicolumn{3}{|c|}{$\beta$-lactoglobuling/pH } & \multicolumn{3}{|c|}{$\alpha$-lactalbumin/pH } & \multicolumn{3}{|c|}{$\beta$-casein $/ \mathrm{pH}$} \\
\hline & 5.5 & 6.0 & 6.5 & 5.5 & 6.0 & 6.5 & 5.5 & 6.0 & 6.5 \\
\hline 25 & $12 \pm 2$ & $20 \pm 3$ & $-{ }^{b}$ & $23 \pm 6$ & $22 \pm 2$ & 14 & $27 \pm 4$ & $20 \pm 3$ & $14 \pm 2$ \\
\hline 50 & $14 \pm 2$ & $20 \pm 3$ & - & $26 \pm 4$ & $22 \pm 2$ & 13 & $27 \pm 3$ & $20 \pm 2$ & $12 \pm 2$ \\
\hline 60 & $22 \pm 2$ & $20 \pm 3$ & - & $24 \pm 8$ & $23 \pm 2$ & 17 & $27 \pm 3$ & $23 \pm 2$ & $14 \pm 2$ \\
\hline 70 & $25 \pm 5$ & $20 \pm 3$ & $* c$ & $27 \pm 8$ & $22 \pm 2$ & 16 & $28 \pm 2$ & $23 \pm 2$ & $*$ \\
\hline 80 & $32 \pm 2$ & $23 \pm 3$ & * & $27 \pm 8$ & $23 \pm 2$ & 17 & $29 \pm 3$ & $23 \pm 2$ & * \\
\hline charge/protein & $-5.1^{d}$ & $-7.1^{d}$ & $-8.2^{d}$ & $-1.3^{d}$ & $-2.4^{d}$ & $-3.4^{d}$ & $-0.8^{e}$ & $-2.7^{e}$ & -4.4 \\
\hline
\end{tabular}

${ }^{a}$ Mean and standard deviation values were calculated using the data from two different batches. ${ }^{b}$ Dash symbol $(-)$ marks the measurements that have been unsuccessful because of the very unstable signal. ${ }^{c}$ Preparations marked with asterisk $\left({ }^{*}\right)$ precipitated immediately upon mixing. ${ }^{d}$ Net molecular charge calculated using PROPKA. ${ }^{41,42}$ (See the Supporting Information for details.) ${ }^{e}$ Net charge of the unfolded protein calculated by Protein Calculator v. 3.3. (See the Supporting Information.)

NJ). To avoid large mixing heats, the stock solutions of both CS and the proteins were prepared in the same buffer, $5 \mathrm{mM}$ sodium phosphate, $\mathrm{pH}$ 6.0. The CS solution with a concentration of 0.5 to $2 \mathrm{mg} / \mathrm{mL}$ was loaded into the injection syringe, and the titration chamber was filled with the protein solution. One experiment consisted of 20-50 consecutive injections with the volume of 5-10 $\mu \mathrm{L}$. Usually, each experiment started with one low volume preinjection $(1-3 \mu \mathrm{L})$, which was typically excluded from the fitting. The titration experiments were performed under continuous stirring at $250 \mathrm{rpm}$ at $T=25$ and $50{ }^{\circ} \mathrm{C}$. Reproducibility test was done in triplicates for the CS- $\alpha$-la system. Other titration experiments were done once, and the reported errors represent the confidence intervals of the fit.

ITC Data Analysis: McGhee-von Hippel Model. Analysis of the experimental data using a standard model for one set of identical noninteracting binding sites was not always successful. A more appropriate formalism for these experiments is the McGhee-von Hippel model for cooperative ligand binding to linear macromolecules. ${ }^{25,26}$ In this model, the macromolecule is considered to be a chain of $N$ repeating units, and the ligand binds to overlapping binding sites with a size of $L$ units. The binding of a single ligand molecule is characterized by the intrinsic binding parameters, such as dissociation constant $(k)$ and binding enthalpy $(\Delta H)$. In addition, the binding of a ligand adjacent to the already bound one is characterized by the cooperative binding parameters: cooperativity constant $(\omega)$ and cooperativity enthalpy $(\Delta h)$. A complete description of the methodology and the data analysis has been previously reported. ${ }^{26}$

The McGhee-von Hippel model is based on several simplifications because it considers a local ligand binding with average thermodynamic parameters. It does not account for either ligand shape or global effects, such as long-range charge-charge interactions. It also does not distinguish between ligand orientations on the linear macromolecule. For example, this model has limited applicability to proteins, which are charged molecules, with nonspherical shapes and heterogeneous electrical charge distribution and possibly different orientations upon binding. An additional limitation of the model is the assumption of linear macromolecule of infinite length $N$. However, when the ratio $N / L$ is $>30$, the error introduced by this approximation is negligible. This requirement is satisfied for all CS-protein systems used in this study. Despite these limitations, the model reproduces experimental data fairly well.

Nonlinear regression analysis was performed in Origin 7.0 (OriginLab, Northampton, MA) using several adjustable parameters described above: intrinsic dissociation constant $(k)$, intrinsic binding enthalpy $(\Delta H)$, cooperativity constant $(\omega)$, cooperativity enthalpy $(\Delta h)$, and the length of the protein binding site $(L)$, expressed as a number of sugar units. Initially, all data were analyzed with the noncooperative binding model. When this did not produce a satisfactory fit, showing large deviation between the fitting curve and the data, cooperativity parameters were employed. An additional adjustable parameter $q_{\mathrm{d}}$ was introduced to account for a nonzero dilution heats.

The molecular weight of CS used in this work was $213000 \mathrm{~g} / \mathrm{mol}$, and thus the length of the CS molecule, $N$, was estimated to be 1265 sugar units. (See the Supporting Information.) Also, because the linear macromolecule (CS) was loaded in the injection syringe and injected into the protein (ligand) solution, the experiments were reverse titrations and therefore were analyzed accordingly. ${ }^{26}$

Differential Scanning Calorimetry. The thermal stability measurements were done either on MicroCal VP-DSC (Piscataway, NJ) or on Nano-DSC (TA Instruments, New Castle, DE) instruments using the scanning rate of $1^{\circ} \mathrm{C} / \mathrm{min}$. All particle samples were made at room temperature, using the same procedure as described in the "Preparation 

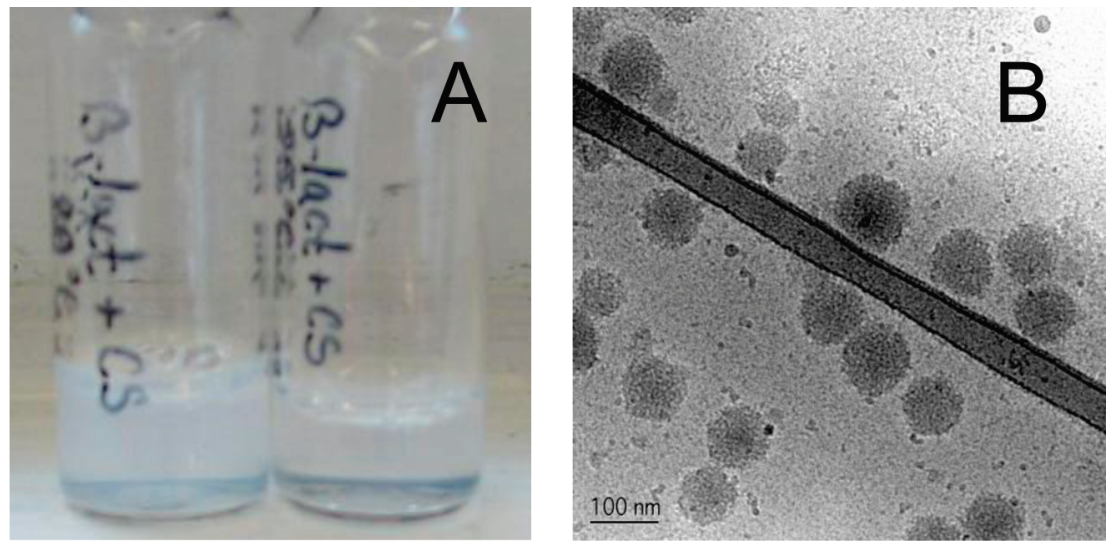

Figure 1. (A) Visual comparison of the particles made of $1 \mathrm{mg} / \mathrm{mL} \beta$-lactoglobulin and $1 \mathrm{mg} / \mathrm{mL}$ chitosan at $\mathrm{pH} 6.0$. The formulation on the right-hand side was made at $25^{\circ} \mathrm{C}$, whereas the one on the left-hand side was made at $70{ }^{\circ} \mathrm{C}$. (B) Cryo-TEM image of the sample of particles prepared at $\mathrm{pH} 6.0$ and $70^{\circ} \mathrm{C}$.

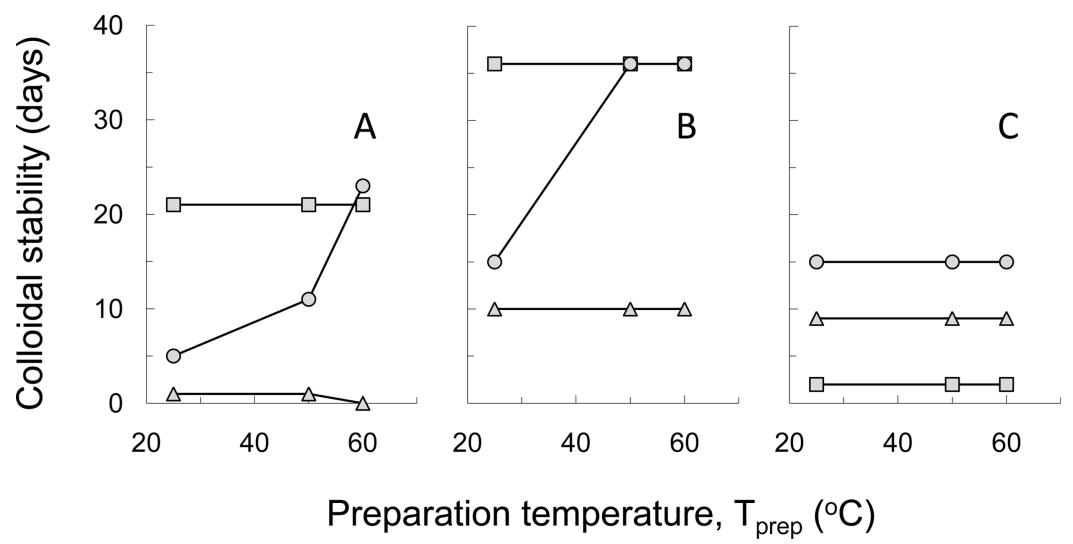

Figure 2. Overview of colloidal stability measurements on chitosan-protein particles as a function of preparation $\mathrm{pH}$ and temperature. Procedure for evaluation of colloidal stability is described in the Materials and Methods section. Data for (A) $\beta$-lactoglobulin, (B) $\alpha$-lactalbumin, and (C) $\beta$-casein. The lines connect data points for the same $\mathrm{pH}$ value, where triangles designate $\mathrm{pH}$ 6.5, circles, $\mathrm{pH}$ 6.0, and the squares, $\mathrm{pH}$ 5.5.

of Chitosan-Protein Particles" section. The concentrations of CS and the protein were $1 \mathrm{mg} / \mathrm{mL}$ each, and the buffer was at $\mathrm{pH} 6.0$. Reversibility of the thermal denaturation transitions of proteins alone and with CS was investigated as well.

\section{RESULTS}

Formation of the Chitosan-Protein Particles. Preparation of the particles by mixing CS and protein solutions was done at several temperatures, marked $T_{\text {prep }}$ in Tables 2 and 3. A preparation was considered to be successful if the particles formed spontaneously, which was observed by the appearance of opacity. Figure 1A shows an example of the particles made with $\beta$-lg at 25 and $70{ }^{\circ} \mathrm{C}$ at $\mathrm{pH}$ 6.0. Despite the similar composition of the two samples, they are visually different, indicating that temperature has an influence on the nanoparticle formation. In some cases, it was not possible to achieve stable suspensions. For example, both $\beta$-lg and $\beta$-ca nanoparticles prepared at $\mathrm{pH} 6.5$ at high temperatures, $\mathrm{T}$ $=70$ and $80^{\circ} \mathrm{C}$, precipitated immediately following the formation.

The size (Table 2) and the $\zeta$-potential (Table 3 ) of the particles were determined by DLS immediately after preparation. Typically, the CS-protein suspensions showed bimodal scattering distribution (data not shown). A low intensity peak located below $100 \mathrm{~nm}$ was attributed to protein micelles, a fact established by DLS experiments on pure proteins at $1 \mathrm{mg} / \mathrm{mL}$. The high-intensity peak was assigned to the presence of CS-protein particles with the diameter of $\sim 200-550 \mathrm{~nm}$. No obvious correlation between the size of nanoparticles and the preparation $\mathrm{pH}$ or temperature was observed. The $\zeta$-potential showed a minimal variation on the preparation conditions, and it was most stable around $\mathrm{pH} 6.0$, maintaining a value of $\sim 20 \mathrm{mV}$ for all three proteins at all temperatures. Cryo-TEM images (Figure 1B) showed spherical-shaped particles with a diameter in the range of $100 \mathrm{~nm}$. The smaller size observed by Cryo-TEM compared with the DLS technique is considered to be due to the preparation procedure of the samples for imaging experiments.

Colloidal Stability. Evaluation procedure for assessing the colloidal stability of nanoparticles is described in the "Colloidal Stability of the Chitosan-Protein Particles" subsection. As expected, this parameter is affected by $\mathrm{pH}$ of the preparation buffer (Figure 2), although the extent of this trend is different for the three model proteins. The stability of the complexes formed between CS and $\beta$-ca (Figure 2C) shows the least variation with $\mathrm{pH}$, and it is not affected by temperature in the range of $25-60^{\circ} \mathrm{C}$.

Because $\beta$-ca is unfolded at all temperatures, whereas the other two proteins are folded below $60^{\circ} \mathrm{C}$, a true comparison between 


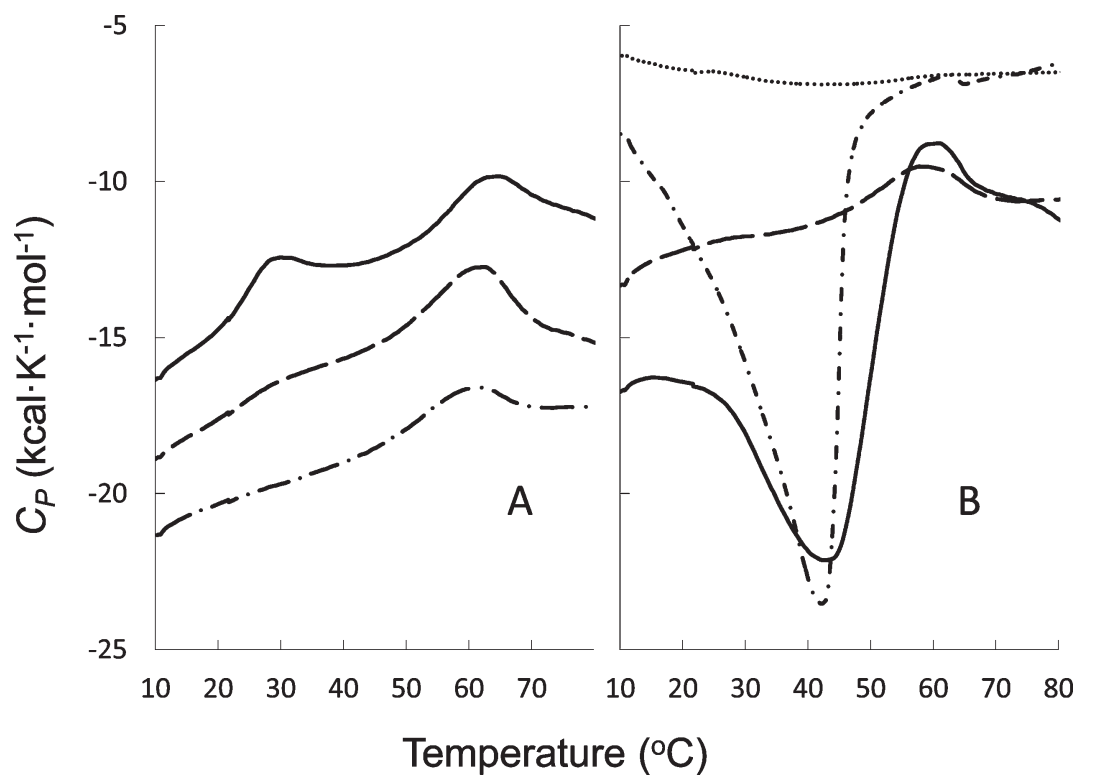

Figure 3. Thermal unfolding curves of $\alpha$-lactalbumin, chitosan and their mixtures at $\mathrm{pH}$ 6.0. The traces are shifted relative to each other along the $y$ axis for illustration purposes. (A) $1 \mathrm{mg} / \mathrm{mL} \alpha$-lactalbumin in buffer (solid line) and with chitosan at $0.1 \mathrm{mg} / \mathrm{mL}$ (dashed) and $0.4 \mathrm{mg} / \mathrm{mL}$ (dashed-dotted). The latter is the sample taken from the ITC cell after a titration experiment at $50{ }^{\circ} \mathrm{C}$. (B) Thermal reversibility tests. CS- $\alpha$-lactalbumin mixture at $1 \mathrm{mg} / \mathrm{mL}$ each: first scan (solid line), rescan (dashed line). Pure CS at $1 \mathrm{mg} / \mathrm{mL}$ : first scan (dashed-dotted line) and a rescan (dotted line).

all three can be made only at higher temperatures, that is, when $\alpha$-la and $\beta$-lg are denatured. However, at 70 and $80^{\circ} \mathrm{C}$, some nanoparticles show an increased propensity for aggregation (Table 2), which is easily observed by appearance of large white clumps. For this reason and for the benefit of presentation clarity, the high-temperature data are not included in Figure 2.

At temperatures between 25 and $60{ }^{\circ} \mathrm{C}$, both $\alpha$-la and $\beta$-lg form the most stable particles at $\mathrm{pH} 5.5$, whereas their stability is minimal at $\mathrm{pH}$ 6.5. At this $\mathrm{pH}$ value, $\mathrm{CS}$ is expected to play the major role in inducing precipitation of the complexes because its charge, and therefore the solubility, become lower, resulting in precipitation. Contrary to the above, the CS- $\beta$-ca particles have the least colloidal stability at $\mathrm{pH} 5.5$, indicating that the repulsive interactions of the positive charges on CS are screened better by $\beta$-ca than by the other two proteins.

In most cases, the preparation temperature had no influence on the colloidal stability of the nanoparticles. An unexpected result was obtained for CS- $\alpha$-la and CS- $\beta$-lg nanoparticles prepared at $\mathrm{pH}$ 6.0, where the stability increased with the preparation temperature. This phenomenon could not be explained on the basis of electrostatic interactions because those did not depend on temperature.

Thermal Stability. Thermal stability of the proteins in the presence or absence of CS was investigated by DSC. As expected, the natively unfolded $\beta$-ca did not show any denaturation transition in the temperature range from 20 to $90{ }^{\circ} \mathrm{C}$, and the addition of CS did not affect this behavior (data not shown). The melting transition of $\beta$-lg was irreversible, with the $T_{\mathrm{m}} \approx 80^{\circ} \mathrm{C}$ (data not shown). The addition of CS had no effect on either protein transition temperature or reversibility of the unfolding. However, it had a profound effect on the shape of the unfolding peak, which became tall and narrow. These data could be fitted to the non-two-state unfolding model, which gave the $H_{\text {cal }} / H_{\text {vh }}$ ratio of $\sim 0.2$, suggesting that the presence of $\mathrm{CS}$ induced selfassociation $^{27}$ of the $\beta$-lg molecules.

In contrast with $\beta$-lg, thermal denaturation of $\alpha$-la was reversible both with and without CS. The two transitions present in the thermograms of the pure protein (Figure 3) were due to the two forms, which differ by the state of binding to $\mathrm{Ca}^{2+}$. The low-temperature peak corresponded to the apo- form and the higher temperature one to the $\mathrm{Ca}^{2+}$-bound form, ${ }^{28}$ which was confirmed by conducting DSC experiments in the presence of $1 \mathrm{mM}$ EDTA (data not shown). Upon the addition of $0.1 \mathrm{mg} / \mathrm{mL}$ CS, the low-temperature peak disappeared. Accordingly, the high-temperature peak became larger, which indicated that the protein has bound additional $\mathrm{Ca}^{2+}$. Because CS is known for its ability to bind $\mathrm{Ca}^{2+}, 29,30$ the trace amounts of this ion may be present in our supply in the form of ash. Indeed, the ash content reported by NovaMatrix is $<1 \%$. Consequently, a highly specific binding between $\alpha$-la and $\mathrm{Ca}^{2+}\left(K=2.9 \times 10^{8} \mathrm{M}^{-1}\right)^{28}$ results in the removal of calcium from $\mathrm{CS}$, which affinity for the divalent ions is at least two orders of magnitude lower. ${ }^{31,32}$ Further increase in the CS concentration leads to a slight decrease in the $T_{\mathrm{m}}$ of protein denaturation transition.

When the CS concentration was equal to $1 \mathrm{mg} / \mathrm{mL}$, protein denaturation transition could no longer be clearly identified because of the interference from a large exothermic peak associated with the thermally induced changes of CS. This peak was only observable on the first scan but not on the rescan of the $\mathrm{CS}$-protein mixtures (Figure $3 \mathrm{~B}$ ), which was similar to the behavior of pure CS. The particles prepared at high temperature also lacked the exothermic transition, indicating that it could be detected only on nonheated samples. This observation was confirmed by running an experiment of the sample titrated with $\mathrm{CS}$ at $50{ }^{\circ} \mathrm{C}$ in the ITC cell and consequently loaded into DSC (Figure 3A).

It must be noted that the exothermic transition, attributed to the thermal changes of CS, is not detected at $0.1 \mathrm{mg} / \mathrm{mL}$ of polysaccharide (compare CS-protein scans in Figure 3A,B). This might indicate that the conformation of the polysaccharide is different at different concentrations. A similar observation was made on a $190000 \mathrm{~g} / \mathrm{mol} \mathrm{CS}$ with DD of $88 \%$ by Philippova et $\mathrm{al}^{22}$ Following the changes in fluorescence of a hydrophobic 


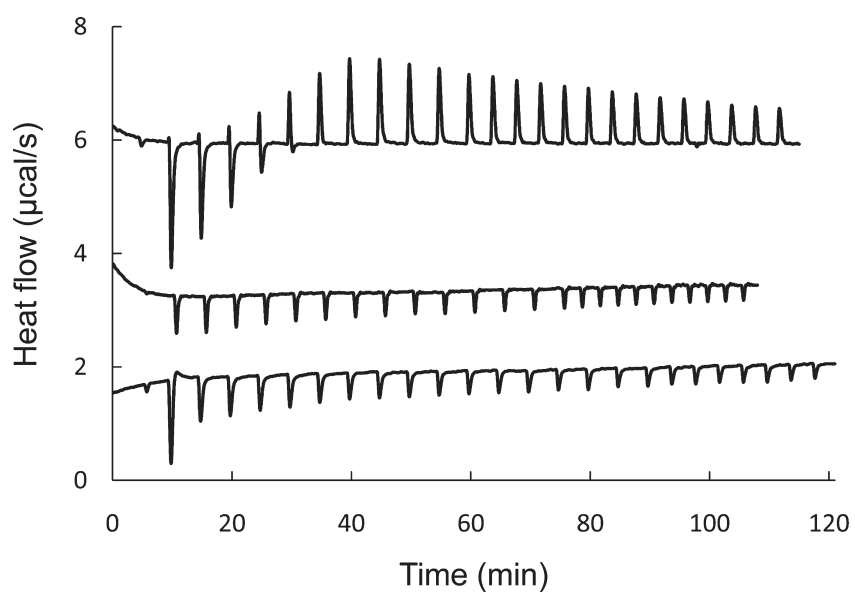

Figure 4. ITC experiment conducted on $\alpha$-lactalbumin titrated with chitosan at 50 (top trace) and $25^{\circ} \mathrm{C}$ (bottom trace). The middle trace represents a reference titration of chitosan into buffer at $T=50{ }^{\circ} \mathrm{C}$. Concentrations of both the titrate and the titrant are $1 \mathrm{mg} / \mathrm{mL}$.

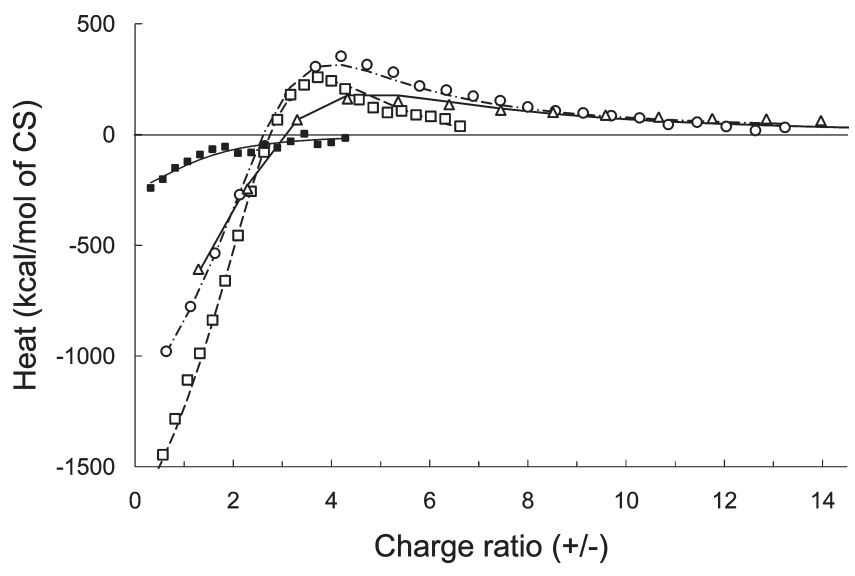

Figure 5. Comparison of the binding isotherms between CS and $\alpha$ lactalbumin at 25 (black symbols) and $50{ }^{\circ} \mathrm{C}$ (gray symbols) as well as their dependence on the concentration of the reactants: squares, $-1 \mathrm{mg} / \mathrm{mL} \mathrm{CS}$ and $1 \mathrm{mg} / \mathrm{mL} \alpha$-la; circles, $-2 \mathrm{mg} / \mathrm{mL} \mathrm{CS}$ and $1 \mathrm{mg} / \mathrm{mL}$ $\alpha$-la; triangles, $-2 \mathrm{mg} / \mathrm{mL} \mathrm{CS}$ and $0.5 \mathrm{mg} / \mathrm{mL} \alpha$-la. The lines are the fitting curves to the lattice model.

probe pyrene, the authors showed that at concentrations above $\sim 1 \mathrm{mg} / \mathrm{mL}, \mathrm{CS}$ was able to form "intermolecular aggregates" characterized by the appearance of extended hydrophobic domains.

Energetics of Chitosan-Proteins Interaction. The investigation of the binding energetics between CS and the proteins was done at $\mathrm{pH} 6.0$, where the preparation temperature had a positive effect on the colloidal stability of the particles. Figure 4 shows a comparison of two titration experiments of $\alpha$-la conducted at two different temperatures. The fast re-establishment of equilibrium after each injection indicated that the binding was not affected by slow aggregation-like processes. At room temperature (Figure 4, bottom trace), the injection heats were exothermic and low in value, whereas at $50^{\circ} \mathrm{C}$ (top trace), the initial exothermic reaction was followed by an additional endothermic stage. This effect was not due to the positive heat of dilution of CS, as indicated by the reference titration shown in Figure 4 (middle trace).

Isotherms obtained with $\alpha$-la at room temperature (Figure 5) were fitted to McGhee-von Hippel model with no cooperativity.
The results, summarized in Table 4, indicate a weak binding with an enthalpy of $-1.5 \pm 0.4 \mathrm{kcal} / \mathrm{mol}$ of protein, the size of the protein binding site, $L$, of three sugar units, and the dissociation constant $1.9 \pm 0.7 \times 10^{-4} \mathrm{M}$.

At $50{ }^{\circ} \mathrm{C}$, the titration data with $\alpha$-la could only be fitted to the model, which accounts for cooperative interactions between protein molecules. The enthalpy of binding to CS was low, 1 to $2 \mathrm{kcal} / \mathrm{mol}$, and the reaction was dominated by the negative enthalpy of protein-protein interactions upon their packing along the polysaccharide chain. The binding affinity was an order of magnitude higher than that at room temperature, and the size of the binding site was larger $(L=8$, Table 4$)$.

The same trend was observed for $\beta$-lg (data not shown), where the binding mode changed from noncooperative at room temperature to highly cooperative at $50{ }^{\circ} \mathrm{C}$. According to the fitting parameters (Table 4), $\beta$-lg occupied a larger area than $\alpha$-la at both temperatures. (See parameter $L$ in Table 4.) This observation is somewhat in agreement with the larger size of $\beta$-lg, compared with $\alpha$-la, as their respective molecular weights are $\sim 18$ and $\sim 14 \mathrm{kDa}$. However, this difference can also be due to other factors, such as the difference in the relative orientation of the proteins upon condensation on CS or because saturation of CS charges requires fewer $\beta$-lg than $\alpha$-la molecules.

The thermodynamic parameters for $\beta$-lg can be compared to a similar study, ${ }^{33}$ where the interaction between CS (15000 g/ mol, DD 85\%) and the protein was studied at $30{ }^{\circ} \mathrm{C}$ in the $\mathrm{pH}$ range from 3 to 7 . The authors used the "single site" model to fit the data. The obtained number of sugar units per protein, 6, was much smaller than the one found in this work (Table 4). Similar to Guzey and McClements, ${ }^{33}$ we have calculated the binding enthalpy per mole of CS using the heat of the first injection (at $T=25^{\circ} \mathrm{C}$ ) and parameters extracted from data fitting, obtaining -1140 and $-1300 \mathrm{kcal} / \mathrm{mol}$, respectively. These values are in good agreement with the previously reported data at $T=30^{\circ} \mathrm{C}$ calculated from the first injection heat, $-1561 \mathrm{kcal} / \mathrm{mol}$, and from the "single site" fitting results, $-1684 \mathrm{kcal} / \mathrm{mol} .{ }^{33}$ The higher enthalpy values obtained in the previous study may be due to the different experimental temperature or because of the large difference in molecular weight of the CS, namely, $15000 \mathrm{~g} / \mathrm{mol}$ used in the previous study ${ }^{33}$ versus $213000 \mathrm{~g} / \mathrm{mol}$ in this work. Also, in the previous study, the data were analyzed with the classic model of specific independent binding sites. An advantage of using the McGhee-von Hippel binding model, however, is that it better describes molecular details of the CS-protein system, such as a lack of binding specificity as well as a possibility of cooperative interaction between bound ligands. In addition, with the help of the lattice model, it is possible to separate contributions from different binding events, such as binding of the protein to CS versus interaction between the protein molecules, bound next to each other on the polysaccharide chain.

It is important to note that formation of the particles is partially irreversible or coupled to the formation of a kinetic barrier because: (a) the particles prepared at the elevated temperatures differ from the ones made at room temperature, even after they have been cooled and (b) there seems to be no immediate dissociation of CS and proteins when suspensions of the particles are diluted in the preparation buffer. Also, the apparent irreversibility could be a consequence of a coupling between protein binding and the changes in accessibility to the binding sites on CS. In light of the above, it is essential to make sure that the binding curves are unaffected by the relative concentrations of the titrant and the titrate, which has been 
Table 4. Thermodynamic Parameters for Chitosan Interaction with Model Proteins, Calculated Using McGhee-von Hippel Model $^{a}$

\begin{tabular}{|c|c|c|c|c|c|c|}
\hline protein & $T\left({ }^{\circ} \mathrm{C}\right)$ & $k(\mu \mathrm{M})$ & $\Delta H(\mathrm{kcal} / \mathrm{mol})^{b}$ & $\omega$ & $\Delta h(\mathrm{kcal} / \mathrm{mol})$ & $L$ \\
\hline \multirow[t]{2}{*}{$\alpha$-lactalbumin ${ }^{c}$} & 25 & $190 \pm 70$ & $-1.5 \pm 0.4$ & & & 3 \\
\hline & 50 & $40 \pm 10$ & $1.1 \pm 0.4$ & $2.5 \pm 0.6$ & $-30 \pm 2$ & 8 \\
\hline \multirow[t]{2}{*}{$\beta$-lactoglobulin ${ }^{d}$} & 25 & $1.9 \pm 0.5$ & $-11.3 \pm 0.4$ & & & 11 \\
\hline & 50 & $40 \pm 10$ & $-4 \pm 1$ & $37 \pm 9$ & $-14 \pm 1.0$ & 25 \\
\hline \multirow[t]{2}{*}{ 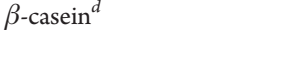 } & 25 & $0.9 \pm 0.7$ & $-14 \pm 2$ & $1.4 \pm 0.6$ & $30 \pm 5$ & 12 \\
\hline & 50 & $8 \pm 2$ & $-1.2 \pm 0.4$ & $14 \pm 7$ & $-24 \pm 4$ & 21 \\
\hline \multirow[t]{2}{*}{ human growth hormone ${ }^{d}$} & 25 & $32 \pm 4$ & $-1.4 \pm 0.1$ & & & 3 \\
\hline & 50 & $960 \pm 110$ & $-5 \pm 1$ & & & 10 \\
\hline
\end{tabular}

${ }^{a}$ Intrinsic dissociation constant, $k$; intrinsic enthalpy (CS-protein binding), $\Delta H$; cooperativity enthalpy (protein-protein interaction), $\Delta h$; cooperativity constant, $\omega$; and the length of binding site, expressed as a number of sugar units, $L .{ }^{b}$ Enthalpy of interaction between chitosan and proteins is per mole of protein. ${ }^{c}$ Triplicate measurements. ${ }^{d}$ Error represents the confidence intervals of the fit.

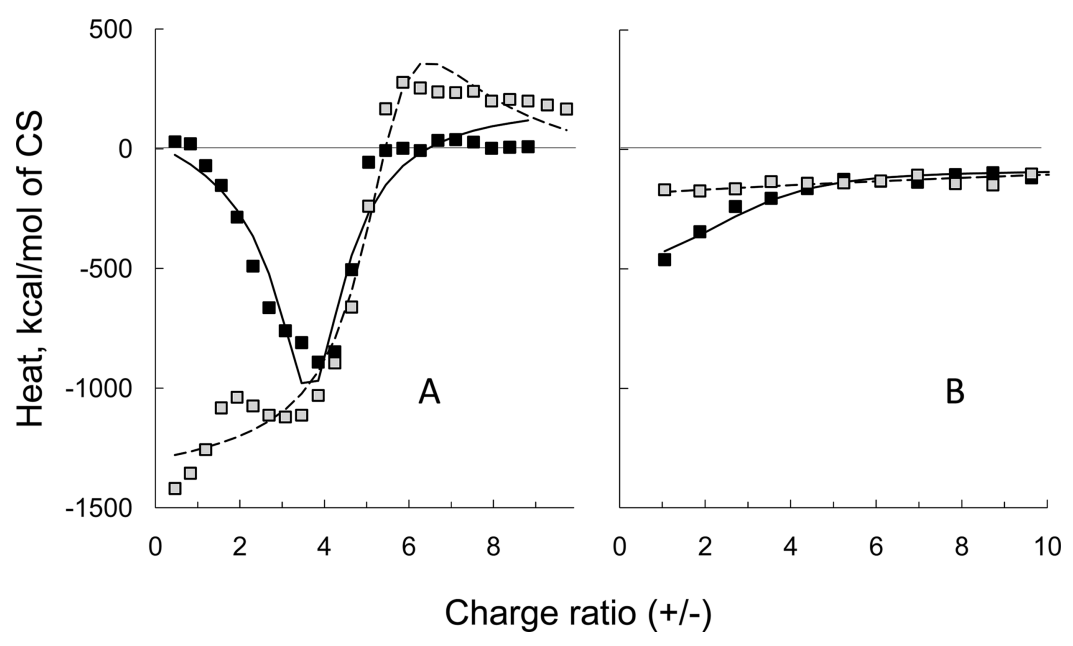

Figure 6. Binding isotherms of chitosan injected into (A) $\beta$-ca and (B) hGH at different temperatures. $T=25$ (closed symbols) and $50{ }^{\circ} \mathrm{C}$ (open symbols). Both the titrant and the titrate were at $1 \mathrm{mg} / \mathrm{mL}$. The curves represent the best fits to McGhee-von Hippel model; solid line, at $25^{\circ} \mathrm{C}$; broken line, at $50^{\circ} \mathrm{C}$.

shown on the CS- $\alpha$-la system by repeating the experiments while varying the concentrations of the reactants. Results, presented in Figure 5 and Table 4, show relatively large standard deviation values for $\Delta H$, indicating that changes in concentration affect mostly the enthalpies of interaction between CS and the protein. However, neither the charge ratio, at which the exothermic reaction becomes endothermic, nor the cooperativity enthalpy, $\Delta h$, seem to be affected (Figure 5 and Table 4 ). All of these features indicate a predominantly reversible process, justifying the attempts of fitting this interaction to equilibrium models.

Unlike the two other proteins, interaction of $\beta$-ca with CS is more complicated and cannot be properly described within the frame of McGhee-von Hippel model either with or without cooperativity contribution, which becomes apparent upon evaluation of quality of the fitting curves. The ITC traces for the titrations of $\beta$-ca with CS at different temperatures are included in the Supporting Information (Supporting Figure 1), whereas results of the analysis are presented in Figure 6. The obtained fits deviate significantly from the data (Figure 6A), suggesting that other processes, not accounted for by the lattice theory, are involved. Nevertheless, the results of fitting are included in the Table 4 for comparative purposes, where it can be seen that the value for parameter $L$ lies within the range of values obtained for other proteins. Although the appropriate thermodynamic parameters for the interaction of CS with $\beta$-ca could not be calculated, it is clear that the CS- $\beta$-ca particle formation is enthalpically driven, which is apparent from the large negative heats detected by ITC. A contrary example, illustrated in Figure 6B, shows a very weak interaction between $\mathrm{CS}$ and hGH. Neither the enthalpy nor the affinity constant in this system is improved by variation of the formulation temperature (Table 4).

\section{DISCUSSION}

The dependence of the particle-forming ability of CS on solution conditions and on the charge ratio between CS and the complementary anionic molecules is well-known. ${ }^{19,33,34}$ However, because this investigation was aiming at elucidating the role of particle preparation temperature on particle formation and colloidal stability rather than to pursue the optimization of the particle composition, concentrations of both CS and the proteins were maintained constant for all formulations.

Experimental evidence presented in this work suggests that electrostatic forces are only partially responsible for stabilization of the CS-based nanoparticles. Even though the proteins used in this work are all negatively charged at the studied $\mathrm{pH}$ values 
(Table 3 and Supporting Figure 2 of the Supporting Information), their binding characteristics to positively charged CS are different. Furthermore, if the interaction of CS and proteins was purely electrostatic, no binding would be observed beyond the point where one-to-one charge ratio is achieved. However, as illustrated by the ITC data (Figures 5 and 6), saturation of the binding capacity of CS lies beyond simple charge neutralization and varies between the studied proteins. This observation correlates with experimental $\xi$-potential values (Table 3 ), which are positive for all formulations, indicating that stable nanoparticles are achieved, when CS is in surplus.

Preparation temperature has no effect on the colloidal stability of CS- $\beta$-ca nanoparticles (Figure 2C). ITC experiments performed at several different temperatures show a multistage binding pattern, inexplicable within the frame of McGheevon Hippel binding model. A possible explanation for this observation can be found in the special micellization properties of $\beta$-ca, which fulfils its biological function by condensing around the oil drops of milk and thus stabilizing the suspension. In both processes, that is, binding to the oil phase and the self-association into micelles, hydrophobic interactions of $\beta$-ca play a leading role, ${ }^{35,36}$ implying that interaction of this protein with CS is hydrophobic in nature as well. This conclusion is further supported by the evidence that CS itself is able to form hydrophobic domains through intermolecular aggregation, ${ }^{22}$ thus providing potential binding sites for $\beta$-ca molecules. In addition, among the three milk proteins, $\beta$-ca shows the least pronounced dependence of particulate colloidal stability on $\mathrm{pH}$ (Figure 2). Moreover, at $\mathrm{pH} 5.5$, whereas the nanoparticles made with the other two milk proteins show the highest colloidal stability, CS$\beta$-ca complexes have the shortest longevity, thus indicating that the presence of this protein enhances hydrophobically driven association of CS.

The importance of the micelle-forming ability of a protein in the complex formation with CS is supported by ITC experiments with hGH (Figure 6B), where temperature has no effect on particle formation, no cooperativity is observed at either temperature and both the binding affinity and the enthalpy are very low (Table 4). This observation also suggests that the low $\mathrm{pI}$ value (the experimental pI of hGH is 5.3$)^{37}$ is not sufficient to ensure the successful formation of CS complexes.

Another parameter potentially contributing to the stability of CS-protein nanoparticles is the amount or type of protein structure. To address this, the selected milk proteins are structurally very different: $\beta$-ca is intrinsically unfolded, whereas $\alpha$-la and $\beta$-lg are folded and stable to at least $60{ }^{\circ} \mathrm{C}$. In addition, the secondary structure of $\alpha$-la is mostly helical, whereas $\beta$-lg consists predominantly of $\beta$-sheet. Because all of these proteins can successfully form complexes with CS, our results indicate that the presence of the defined secondary structure is not important for binding to CS. Moreover, our DSC data show that CS binds to $\alpha$-la and $\beta$-lg both below and above their respective denaturation transitions (Table 2), which correlates well with a similar study of CS- $\beta$ - $\lg$ interaction, ${ }^{38}$ where the authors conclude that binding to CS does not lead to a net stabilization of either native or denatured protein conformations. The same conclusion can be reached on the basis of reversibility of $\alpha$-la unfolding transition in the presence of CS, which also implies that the binding site to CS is located on the solvent-exposed surface of the protein. This observation is very important for the use of CS as a drug excipient, where it is desirable that a protein is preserved in its native state and that it maintains its active conformation within nanoparticles.
Special attention is paid to the interaction of CS with $\alpha$-la and $\beta$ - $\lg$ at $\mathrm{pH} 6.0$ because at this $\mathrm{pH}$ the increase in preparation temperature improves the colloidal stability of the particulate formulations. Results of ITC studies at different temperatures indicate that saturation of the binding capacity of these proteins at $T=25{ }^{\circ} \mathrm{C}$ requires less CS and the enthalpic effect is lower than that at $T=50^{\circ} \mathrm{C}$. This indicates that at room temperature the binding of $\alpha$-la and $\beta$-lg to CS is weak, in accordance with the previous ITC studies. ${ }^{19,20}$ This further suggests that neither $\alpha$-la or $\beta$-lg is able to utilize CS hydrophobic domains to the same extent as $\beta$-ca, and the complex formation with the polysaccharide relies on other forces, possibly hydrogen bonding.

The use of the McGhee-von Hippel model allows separation of the overall interaction enthalpy into two components, quantifying both the direct binding of proteins to CS, $\Delta H$, and the cooperative interaction between adjacent protein molecules, $\Delta h$. This analysis suggests that cooperativity of the CS-protein interaction appears only at higher temperatures. Also, at $T=$ $50{ }^{\circ} \mathrm{C}$, the largest enthalpic contribution is produced by protein-protein interactions between the neighboring molecules (parameter $\Delta h$ in Table 4) upon their condensation along the polysaccharide chain. This, and the large positive value of $\omega$ at $T=50^{\circ} \mathrm{C}$ (Table 4), imply that improvement of CS- $\alpha$-la and CS$\beta$-lg complex formation is achieved through the appearance of positive cooperativity.

Therefore, a question arises: why do the interprotein interactions, stabilizing CS complexes with $\alpha$-la and $\beta$-lg, occur only at higher temperatures? As suggested by DSC, the improvement in particulate stability with temperature is not due to the conformational changes of the proteins because their unfolding transitions lie above $50{ }^{\circ} \mathrm{C}$ (Figure 3 and the Results section). The DSC experiments on pure CS indicate a presence of exothermic transition between 25 and $50{ }^{\circ} \mathrm{C}$ (Figure 3). Whereas such thermal effects are usually assigned to structural changes, our data provide no information on the molecular details of those. Although, the temperature dependence of the intrinsic viscosity of several CSs (including the one with MW $=213000 \mathrm{~g} / \mathrm{mol}$ and $83 \% \mathrm{DD})$ is linear between 10 and $50{ }^{\circ} \mathrm{C},{ }^{39}$ this fact is not sufficient to conclude that CS does not undergo any conformational changes in this temperature range. ${ }^{40}$ For example, it has been shown that hydrophobic aggregation of CS upon increasing concentration has only minor effect on the intrinsic viscosity. ${ }^{22}$ Another possible explanation for the observed exothermic transition is the solubility changes of CS with temperature. Indeed, at $\mathrm{pH}$ 6.0, the soluble fraction of the $15000 \mathrm{~g} / \mathrm{mol} \mathrm{CS}$ in $5 \mathrm{mM}$ buffer at $1 \mathrm{mg} / \mathrm{mL}$ is only $80 \%,{ }^{33}$ suggesting that the same can be true for the type of CS used in this study. Whether increasing the temperature induces conformational changes or alters the fraction of soluble CS, the process results in the redistribution of protein binding sites so that the bound proteins acquire an ability to occupy neighboring spaces and pack more efficiently along the polysaccharide chain. The favorable self-association energy due to this packing interaction is the additional stabilizing force contributing to the overall stability of the CS nanoparticles. The increase in temperature implies a reduction in the apparent binding capacity of CS because at higher temperature more CS has to be added to saturate the protein, or, in other terms, the size of the binding site, $L$, increases with temperature. These data correlate with the storage stability studies, which show that particles prepared at higher temperature are more stable compared with the ones prepared at room temperature. 
Scheme 1. Hypothetical Model of the Thermally Induced Changes in the CS-Protein Interaction within Nanoparticles

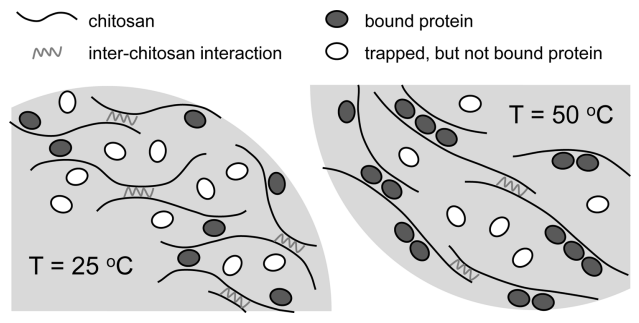

\section{CONCLUSIONS}

In conclusion, our results indicate that electrostatic interactions are rarely the only forces participating in the formation and stabilization of the CS-protein complexes. Both hydrophobic effect and hydrogen bonding are likely to contribute as well and thus can be successfully exploited for the purpose of creating colloidally stabilized particles. Additional favorable stabilization can be accomplished by protein-protein interactions when the proteins exhibit a tendency to self-associate or form micelles.

Comparison of the structural properties of investigated proteins suggests that the presence of the secondary/tertiary structure (or its type) is not essential for protein ability to form complexes with CS. Moreover, because CS has only minor influence on protein thermal denaturation transition, it is likely that the CS binding sites are located on the protein surface, which would be important for ensuring the preservation of protein's active conformation within pharmaceutical formulations.

Finally, this work presents two examples of CS-protein systems, where the preparation temperature plays an important role in the formation of CS-based nanoparticles. We suggest that this effect is caused by thermally induced changes of CS, which result in the appearance of additional protein binding sites. Moreover, it is shown that the enhanced ability of the polysaccharide to interact with proteins at elevated temperatures improves the colloidal stability of CS - protein nanoparticles. A schematic illustration of the thermally induced changes in CS-protein interactions is shown in Scheme 1.

\section{ASSOCIATED CONTENT}

Supporting Information. Calculation of the molecular charge of $\mathrm{CS}$ and the proteins as a function of $\mathrm{pH}$ and additional raw ITC data obtained on CS- $\beta$-ca. system. This material is available free of charge via the Internet at http://pubs.acs.org.

\section{AUTHOR INFORMATION}

\section{Corresponding Author}

${ }^{*}$ Tel: +45 35336346 (H.M.N.), +45 41243786 (M.R.K.). E-mail: hmn@farma.ku.dk, marina_kasi@yahoo.dk.

\section{ACKNOWLEDGMENT}

This work was funded by the Danish Agency for Science, Technology and Innovation. We would like to thank Allan Henriksen and Karina Juul Vissing at University of Copenhagen, Denmark as well as Gunnel Karlsson at the Biomicroscopy Unit, Polymer and Materials Chemistry, Chemical Centre, Lund University, Sweden for technical assistance and Novo Nordisk
A/S for donating hGH and funding VP-DSC. Nano ITC instrument was funded by the Danish National Advanced Technology Foundation.

\section{REFERENCES}

(1) Lee, J. W.; Kim, S. Y.; Kim, S. S.; Lee, Y. M.; Lee, K. H.; Kim, S. J. J. Appl. Polym. Sci. 1999, 73, 113-120.

(2) Kotze, A. F.; Luessen, H. L.; de Leeuw, B. J.; de Boer, B. G.; Verhoef, J. C.; Junginger, H. E. J. Controlled Release 1998, 51, 35-46.

(3) Thanou, M.; Verhoef, J. C.; Junginger, H. E. Adv. Drug Delivery Rev. 2001, 52, 117-126.

(4) Berger, J.; Reist, M.; Mayer, J. M.; Felt, O.; Peppas, N. A.; Gurny, R. Eur. J. Pharm. Biopharm. 2004, 57, 19-34.

(5) Lin, Y. H.; Mi, F. L.; Chen, C. T.; Chang, W. C.; Peng, S. F.; Liang, H. F.; Sung, H. W. Biomacromolecules 2007, 8, 146-152.

(6) Lopez-Leon, T.; Carvalho, E. L.; Seijo, B.; Ortega-Vinuesa, J. L.; Bastos-Gonzalez, D. J. Colloid Interface Sci. 2005, 283, 344-351.

(7) Nafee, N.; Schneider, M.; Schaefer, U. F.; Lehr, C. M. Int. J. Pharm. 2009, 381, 130-139.

(8) Tang, D. W.; Yu, S. H.; Ho, Y. C.; Mi, F. L.; Kuo, P. L.; Sung, H. W. Biomaterials 2010, 31, 9320-9332.

(9) Calvo, P.; Remunan-Lopez, C.; VilaJato, J. L.; Alonso, M. J. J. Appl. Polym. Sci. 1997, 63, 125-132.

(10) Bodmeier, R.; Oh, K. H.; Pramar, Y. Drug Dev. Ind. Pharm. 1989, 15, 1475-1494.

(11) Tao, X.; Sun, X. J.; Su, J. M.; Chen, J. F.; Roa, W. Polymer 2006, 47, 6167-6171.

(12) Shu, X. Z.; Zhu, K. J. Int. J. Pharm. 2002, 233, 217-225.

(13) Ma, Z. S.; Yeoh, H. H.; Lim, L. Y. J. Pharm. Sci. 2002, 91, 1396-1404.

(14) Yoshida, H.; Nishihara, H.; Kataoka, T. Biotechnol. Bioeng. 1994, 43, 1087-1093.

(15) Anal, A. K.; Tobiassen, A.; Flanagan, J.; Singh, H. Colloids Surf., B 2008, 64, 104-110.

(16) Mi, F. L.; Shyu, S. S.; Kuan, C. Y.; Lee, S. T.; Lu, K. T.; Jang, S. F. J. Appl. Polym. Sci. 1999, 74, 1868-1879.

(17) Boonsongrit, Y.; Mitrevej, A.; Mueller, B. W. Eur. J. Pharm. Biopham. 2006, 62, 267-274.

(18) Gan, Q.; Wang, T. Colloids Surf., B 2007, 59, 24-34.

(19) Ma, P. L.; Lavertu, M.; Winnik, F. M.; Buschmann, M. D. Biomacromolecules 2009, 10, 1490-1499.

(20) Boonsongrit, Y.; Mueller, B. W.; Mitrevej, A. Eur. J. Pharm. Biopham. 2007, 69, 388-395.

(21) Zhu, A. P.; Yuan, L. H.; Chen, T.; Wu, H.; Zhao, F. Carbohydr. Polym. 2007, 69, 363-370.

(22) Philippova, O. E.; Volkov, E. V.; Sitnikova, N. L.; Khokhlov, A. R.; Desbrieres, J.; Rinaudo, M. Biomacromolecules 2001, 2, 483-490.

(23) Hossain, M.; Fenton, G. Australas. Biotechnol. 1998, $8,289-294$.

(24) de Kruif, C. G.; Grinberg, V. Y. Colloids Surf., A 2002, 210, $183-190$.

(25) McGhee, J. D.; von Hippel, P. H. J. Mol. Biol. 1974, 86, 469-489.

(26) Velazquez-Campoy, A. Anal. Biochem. 2006, 348, 94-104.

(27) Privalov, P. L.; Potekhin, S. A. Methods Enzymol. 1986, $131,4-51$.

(28) Hendrix, T.; Griko, Y. V.; Privalov, P. L. Biophys. Chem. 2000, $84,27-34$.

(29) Vllasaliu, D.; Exposito-Harris, R.; Heras, A.; Casettari, L.; Garnett, M.; Illum, L.; Stolnik, S. Int. J. Pharm. 2010, 400, 183-193.

(30) Bravo-Osuna, I.; Millotti, G.; Vauthier, C.; Ponchel, G. Int. J. Pharm. 2007, 338, 284-290.

(31) Monteiro, O. A. C.; Airoldi, C. J. Colloid Interface Sci. 1999, 212, 212-219.

(32) Delben, F.; Muzzarelli, R. A. A. Carbohydr. Polym. 1989, 11, 221-232. 
(33) Guzey, D.; McClements, D. J. Food Hydrocolloids 2006, 20, 124-131.

(34) Chen, Y. C.; Wang, C. H.; Lai, L. S.; Lin, K. W. J. Food Sci. 2003, 68, 826-831.

(35) Mikheeva, L. M.; Grinberg, N. V.; Grinberg, V. Y.; Khokhlov, A. R.; de Kruif, C. G. Langmuir 2003, 19, 2913-2921.

(36) Schmidt, D. G.; Payens, T. A. J. J. Colloid Interface Sci. 1972, 39, 655-662.

(37) Pearlman, R.; Bewley, T. A. Pharm. Biotechnol. 1993, 5, 1-58.

(38) Souza, H. K.; Goncalves, M. D.; Gomez, J. Biomacromolecules 2011, 12, 1015-1023.

(39) Chen, R. H.; Tsaih, M. L. Int. J. Biol. Macromol. 1998, 23, 135-141.

(40) Desbrieres, J. Biomacromolecules 2002, 3, 342-349.

(41) Li, H.; Robertson, A. D.; Jensen, J. H. Proteins: Struct., Funct., Bioinf. 2005, 61, 704-721.

(42) Bas, D. C.; Rogers, D. M.; Jensen, J. H. Proteins: Struct., Funct., Bioinf. 2008, 73, 765-783. 